\title{
Results of Combined Chemotherapy and External Beam Radiotherapy for Unilateral Intra-Orbital Retinoblastoma-A Multi-Institutional Study from Mali
}

\author{
Boubacar Togo ${ }^{1 *}$, Fousseyni Traore ${ }^{1 *}$, Konimba Diabaté2, Fatou Sylla ${ }^{3}$, Aïchata Tall2, \\ Affiatou Simaga², Bakarou Kamaté4, Hawa Diall'1, Pierre Togo', Abdoul Karim Doumbia1, \\ Pierre Bey5, Francis Eshun6
}

${ }^{1}$ Department of Pediatrics, Gabriel Toure Hospital, Bamako, Mali

${ }^{2}$ Radiation Therapy Service, National Hospital of Mali, Bamako, Mali

${ }^{3}$ Institute of Tropical Ophthalmology of Africa (IOTA), Bamako, Mali

${ }^{4}$ Department of Histopathology, Hospital of Point G, Bamako, Mali

${ }^{5}$ Curie Institute et AMCC, Paris, France

${ }^{6}$ Phoenix Children's Hospital, Phoenix, AZ, USA

Email: ${ }^{\star}$ togoboubacar2000@yahoo.fr

How to cite this paper: Togo, B., Traore, F., Diabaté, K., Sylla, F., Tall, A., Simaga, A., Kamaté, B., Diall, H., Togo, P., Doumbia, A.K., Bey, P. and Eshun, F. (2019) Results of Combined Chemotherapy and External Beam Radiotherapy for Unilateral Intra-Orbital Retinoblastoma-A Multi-Institutional Study from Mali. Open Journal of Pediatrics, 9, 39-46. https://doi.org/10.4236/ojped.2019.91005

Received: December 26, 2018

Accepted: January 26, 2019

Published: January 29, 2019

Copyright () 2019 by author(s) and Scientific Research Publishing Inc. This work is licensed under the Creative Commons Attribution International License (CC BY 4.0).

http://creativecommons.org/licenses/by/4.0/

\section{c) (i) Open Access}

\begin{abstract}
Retinoblastoma (RB) treatment aims at saving the life and preserving useful vision. In most low-income countries, because of delays in diagnosis, advanced disease presentation is quite common. This prospective study aimed at evaluating the treatment results of orbital $\mathrm{RB}$ with regards to overall survival rate of the patients treated with chemotherapy and radiotherapy. The study was performed from 01 November 2011 to 31 December 2015 in the paediatric oncology unit of Gabriel Touré Teaching Hospital, Bamako, Mali and The Institute of Tropical Ophthalmology of Africa (IOTA), Bamako, Mali. All intra-orbital non-metastatic RB cases not previously treated by chemotherapy or radiotherapy were included in this study. Fourteen patients were included into the study. Median age was 2 years, and sex ratio $2.5(\mathrm{M}=10 ; \mathrm{F}=$ $4)$. Right eye $(n=12,85.7 \%)$ was more often affected than left eye $(n=2$; $14.3 \%)$. Chemotherapy toxicities were mainly haematological including grade 3 anemia $(n=2 ; 7 \%)$ and grade 4 neutropenia $(n=3 ; 11 \%)$. Twelve patients (86\%) were enucleated after neoadjuvant chemotherapy. Two patients $(14 \%)$ abandoned treatment before enucleation. The IRSS pathology staging was: stage IIIa in 6 patients (50\%), and stage II in six patients (50\%). Six children (43\%) received orbital radiotherapy at total dose of $45 \mathrm{~Gy}$; Six children (43\%) achieved complete remission; Overall survival rate was $48 \%$ at 4 years $(95 \%$
\end{abstract}


CI: $22.5 \%-74.4 \%)$. In conclusion, the therapeutic strategy based on neoadjuvant chemotherapy followed by enucleation, adjuvant chemotherapy and external beam radiotherapy, was beneficial in patients with stage III disease, achieving an event-free survival rate of $48 \%$.

\section{Keywords}

Orbital Retinoblastoma, Children, Mali

\section{Introduction}

Retinoblastoma (RB) is the most common intra ocular malignant tumor of infancy and childhood, and represents $3 \%$ of all childhood malignancies. The majority of cases are diagnosed before 2 years of age, and $95 \%$ before 5 years. RB is considered a rare tumor in developed countries, and it represents $3 \%$ of infant cancers [1]. The overall incidence of retinoblastoma is constant worldwide at one case per 15,000 - 20,000 live births, but it is higher in developing countries and as a result, it represents the most common pediatric tumor in the developing world [2] [3]. Neglected or untreated RB can lead to extraocular dissemination mainly to the optic nerve and sclera (Figure 1). Treatment of RB aims at saving the life and preserving useful vision. In most low-income countries, delays in diagnosis result in advanced disease, frequently extraocular. Radiation therapy of retinoblastoma remains controversial as it is fraught with complications especially in very high in infants. Despite these risks, it remains an effective local control measure for the treatment of advanced retinoblastoma. An initial study of retinoblastoma at the unit of pediatric oncology of Bamako showed a survival rate of only 50\% [4]. In 2011 the global alliance against cancer (AMCC) Curie Institute of Paris (a tertiary referral center in France for retinoblastoma) and the teams of Bamako (Gabriel Toure Hospital and IOTA) developed a program for early diagnosis and treatments, including conservative management and orbital rehabilitation of retinoblastoma in Mali [5] [6].

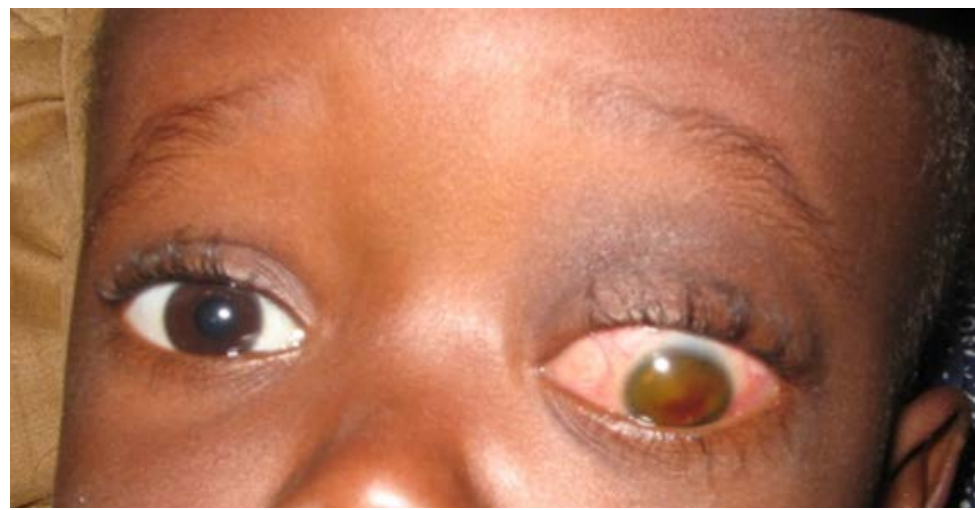

Figure 1. Buphtalmia as a mode of presentation of a unilateral retinoblastoma of the left eye. 


\section{Objectives}

This prospective study aimed at evaluating the treatment outcomes including overall survival of orbital intraocular non-metastatic RB.

\section{Patients and Methods}

The study was performed prospectively from 01 November 2011 to 31 December 2015 (4 years and 2 months duration), in the paediatric oncology unit of Gabriel Touré teaching hospital and in IOTA.

Inclusion criteria were the following: All intra-orbital non-metastatic RB cases, not previously treated by chemotherapy or radiotherapy; patients having no contraindication for study's treatments; patients for whom long-term monitoring is possible and informed consent of parents or legal represent has been obtained.

Geographical representation (urban or rural area) of the patients was documented. At enrolment, all the patients had detailed ophthalmological examination including fundus eye exam under general anaesthesia. Orbito-frontal brain computed tomography (CT scan) and bone marrow and cerebrospinal fluid exam were also performed in all the patients. The international retinoblastoma staging system (IRSS) was used for the classification of patients [7]. All the patients underwent a complete clinical oncology evaluation and routine blood check.

\section{Treatment Strategies}

Therapeutic guidelines of French-African Paediatric Oncology Group (GFAOP), were utilized Figure 2.

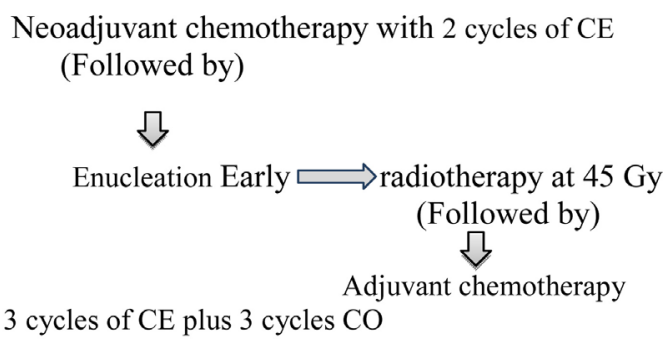

\section{$\square$ Details of chemotherapy courses}

\begin{tabular}{|c|}
\hline 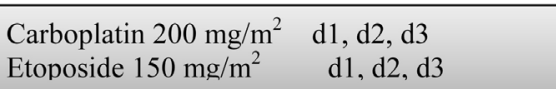 \\
\hline $\begin{array}{l}\text { Cyclophosphamide }\left(300 \mathrm{mg} / \mathrm{m}^{2} / \mathrm{j}\right) \quad \mathrm{d} 1-\mathrm{d} 5 \\
\text { Vincristine } 1,5 \mathrm{mg} / \mathrm{m}^{2} / \mathrm{j} \mathrm{d} 1\end{array}$ \\
\hline
\end{tabular}

NB: weight $<12 \mathrm{~kg}, 2 / 3$ of the dose should be administered

Figure 2. Treatment guidelines of unilateral intra-orbital non metastatic retinoblastoma. 


\subsection{Radiation Therapy}

Radiotherapy was done under a Philips 16-bar scan device. For immobilization of the patient, a three-point thermoformed mask was used, aligned with the laser system. General anaesthesia was performed during simulation and during irradiation. Predictive dosimetry was practiced for the choice of energy and ballistics of irradiation beams with the Xio Software. The technic used was the combination of anterior beam and oblique bundles. The dose delivered was $45 \mathrm{~Gy}$ in in $1.8 \mathrm{~Gy} /$ fraction.

\subsection{Response Criteria}

Complete remission was defined as disappearance of all clinical symptoms and biological signs with medical imaging and ophthalmological exam showing no sign of tumor recurrence. Relapse was defined as any evidence of tumour recurrence regardless of the recurrence site.

\subsection{Statistical Analysis}

Data from medical files of included patients were analysed on IBM SPSS version 20 (SPSS Inc., Chicago, IL). Kaplan-Meier method was used to estimate treated patients' survival, 95\% confidence intervals (CI) and log-rank test to compare survival rates in treated patients according to the different forms of $\mathrm{Rb}$ [8]. Follow-up data for each patient was measured from patient's inclusion in the study up to last data collection. To estimate overall survival (OS), all deaths were considered regardless of causes and survival times of patients who are alive were censored at the date of last contact with the patient up to the date of study closure. The patients who abandoned the treatment were censored at the time of abandonment.

\section{Results}

Fourteen patients were included into the study, from 01 November 2011 to 31 December 2015. Patient's characteristics are summarized in Table 1. Median age was 2 years, and sex ratio $2.5(\mathrm{M}=10 ; \mathrm{F}=4)$.

The diagnostic delay was 15 months. The majority of patients lived in rural areas and had an unfavorable socioeconomic condition $(n=9 ; 65 \%)$. The median distance between the treatment center and the residence of the patients was $150 \mathrm{~km}$. Eighty percent of patients had good nutritional status at admission ( $\mathrm{n}=$ $11)$. Right eye ( $\mathrm{n}=12 ; 85.7 \%)$ was more often affected than left eye $(\mathrm{n}=2$; 14.3\%). At Ophthalmologic evaluation of patients, proptosis accounted for $75 \%$ $(\mathrm{n}=10)$. Two patients had orbital cellulitis, and four patients had red painful eye. All patients received radiological evaluation by CT scan (100\%). The extraorbital involvement according to the CT scan was as follows: Isolated extrascleral involvement $(\mathrm{n}=7 ; 50 \%)$, isolated involvement of orbital part of optic nerve $(n=5 ; 36 \%)$ and isolated involvement of the orbital muscles $(n=2 ; 14 \%)$. Twenty-eight neoadjuvant chemotherapy courses with Etoposide/Carboplatin 
Table 1. Patients characteristics.

\begin{tabular}{|c|c|c|}
\hline Characteristics & Number & Percentage (\%) \\
\hline \multicolumn{3}{|l|}{ Gender } \\
\hline Male & 10 & 71 \\
\hline Female & 4 & 29 \\
\hline \multicolumn{3}{|l|}{ Age (years) } \\
\hline Range & $2-4$ & 100 \\
\hline \multicolumn{3}{|l|}{ Presenting signs } \\
\hline Proptosis & 10 & 75 \\
\hline Orbital cellulitis & 2 & 14.28 \\
\hline Red painful eye & 2 & 14.28 \\
\hline \multicolumn{3}{|l|}{ CT scan features } \\
\hline Extrascleral involvement & 7 & 50 \\
\hline Involvement of orbital part of optic nerve & 5 & 36 \\
\hline Involvement of the orbital muscles & 2 & 14 \\
\hline \multicolumn{3}{|l|}{ IRSS staging } \\
\hline Stage IIIa & 6 & 50 \\
\hline Stage II & 6 & 50 \\
\hline \multicolumn{3}{|l|}{ External beam radiotherapy } \\
\hline Received & 6 & 43 \\
\hline Not received & 6 & 43 \\
\hline \multicolumn{3}{|l|}{ Outcome } \\
\hline Complete remission & 6 & 43 \\
\hline Death & 6 & 43 \\
\hline Treatment abandonment & 2 & 14 \\
\hline
\end{tabular}

were administered. Chemotherapy toxicity was mainly haematological including grade 3 anemia $(n=2 ; 7 \%)$ and grade 4 neutropenia $(n=3 ; 11 \%)$. Twelve patients $(86 \%)$ were enucleated after neoadjuvant chemotherapy. Two patients (14\%) abandoned treatment before enucleation. The pathology staging according IRSS system was respectively: stage IIIa in 6 patients (50\%), and stage II in six patients (50\%). Forty-two adjuvants chemotherapy were administered. Toxicities of these post-operative chemotherapies were mainly haematological and digestive: grade 3 anemia $(n=6 ; 14.3 \%)$, grade 4 neutropenia $(n=11 ; 26.2 \%)$ and grade 3 mucositis $(n=5 ; 11.9 \%)$. No death was linked to these chemotherapy toxicities. Six (43\%) children received orbital radiotherapy at total dose of 45 Gy. Six patients did not receive radiation therapy. At the end of treatment and a median follow-up of two years, six children (43\%) achieved complete remission. Overall survival rate was $48 \%$ at 4 years ( $95 \%$ CI: $22.5 \%-74.4 \%$ ).

\section{Discussion}

Retinoblastoma is a common ocular tumor in sub-Saharan Africa associated 
with long diagnostic delays [9]. The diagnostic delay in our study was 15 months. Ignorance and poverty of families are contributing factors to this delayed diagnosis. The major reason given by parents for delayed presentation was unawareness about the seriousness of the disease (95\%) (Figure 1). Many countries have developed education campaigns with the goal of decreasing diagnostic delay in order to reduce the frequency of advanced disease [10] [11]. In our series, the median age at diagnosis was 2 years, with a sex ratio of 2, 5. In Ghana, Essuman et al. found an average age of 25 months at diagnosis [12]. Proptosis was the most frequent symptom at admission $(\mathrm{n}=10 ; 75 \%)$.

Clinically advanced RB is characterized by proptosis due to orbital extension or optic nerve involvement. The presence of orbital invasion of the intraocular tumor increases the risk of systemic metastasis, associated with poor prognosis [13]. Metastases work-up in our patients did not show distant metastases.

CT scan evaluation showed extra-scleral orbital extension in $60 \%$ of patients $(\mathrm{n}=8)$ and optic nerve involvement in $40 \%(\mathrm{n}=6)$ (Table 1). Other studies in India [14], and in Senegal [15], reported a high percentage of extraocular forms, $37 \%$ and $52 \%$ respectively. The incidence of orbital RB is still very low in developed countries, due to early diagnosis [16]. Treatment of RB requires a multidisciplinary approach including Ophthalmologists, Pediatric Oncologists, Radiation oncologists and Radiologists. Most centers use standard doses of carboplatin and etoposide (CE) and cyclophosphamide/vincristine (CO) courses for neoadjuvant and adjuvant chemotherapy of RB. Neoadjuvant chemotherapy should reduce tumoral volume in severely buphthalmic eyes, reducing the risk of eye rupture during enucleation [17]. The IRSS staging system makes it possible to specify the histological risk factors and stratify patients for adjuvant chemotherapy. However, neoadjuvant chemotherapy affects these risk factors. The pathology staging according IRSS system was as follow: stage IIIa in 6 patients (50\%), and stage II in six patients (50\%). Pant G, found $63.4 \%$ of stage III in a cohort of 41 patients with extraocular RB [18]. Soltani et al. in Morocco found the involvement of orbital part of optic nerve in 58.3\% and extrascleral involvement in 41.6\% [19]. Radiation therapy can treat residual disease after adjuvant chemotherapy. Radiation therapy can lead to growth retardation of the irradiated territory as well as endocrine sequelae due to the irradiation of the pituitary gland. Secondary sarcomas can also occur in the radiation field. Radiation exposure of young children generally increases the risk of developing secondary malignancy. This risk of second cancer is higher when there is germline mutation of the RB1 gene [20].

Patients receive a dose of $45 \mathrm{~Gy}$ to the target volume by two electron beams over 5 weeks, with fractions of $1.8 \mathrm{~Gy}$ (for children under 12 months old) to 2 Gy (for children over 12 months). Six patients (43\%) did not receive radiation because of the long waiting time and unfortunately died of progressive disease. Overall survival rate was $48 \%$ at 4 years (95\% CI 22.5\% - 74.4\%). In India, Radhakrishnan and Bakhshi found respectively a survival rate of $40.4 \%$ and $34 \%, 7 \%$ [21] [22]. 


\section{Conclusion}

The therapeutic strategy based on neoadjuvant chemotherapy followed by enucleation, adjuvant chemotherapy and external beam radiotherapy, was beneficial in patients with stage III disease of the IRSS, achieving an event-free survival rate of $48 \%$.

\section{Acknowledgements}

The authors thank for their support GFAOP, AMCC, Curie Institute in Paris, la Fondation Sanofi Espoir through its program "My Child Matters".

\section{Conflicts of Interest}

The authors declare no conflict of interest.

\section{References}

[1] Doz, F. (2006) Retinoblastoma: A Review. Archives de Pédiatrie, 13, 1329-1337. https://doi.org/10.1016/j.arcped.2006.06.017

[2] Chintagumpala, M., Chevez-Barrios, P., Paysse, E.A., et al. (2007) Retinoblastoma. Review of Current Management. Oncologist, 12, 1237-1246. ps://doi.org/10.1634/theoncologist.12-10-1237

[3] Ali, A.A., Lsheikh, S.M., Elhaj, A., et al. (2011) Clinical Presentation and Outcome of Retinoblastoma among Children Treated at the National Cancer Institute (NCI) in Gezira, Sudan: A Single Institution Experience. Ophthalmic Genetics, 32, 122-125. https://doi.org/10.3109/13816810.2010.546822

[4] Togo, B., Fatou Sylla, F., Traore, F., et al. (2010) 30 Month Prospective Study on the Treatment of Retinoblastoma in the Gabriel Touré Teaching Hospital. Bamako, Mali. British Journal of Ophthalmology, 94, 467-469. https://doi.org/10.1136/bjo.2009.159699

[5] Traore, F., Togo, B., Sylla, F., et al. (2013) Le rétinoblastome: Etat des lieux au Mali et programme d'aide au diagnostic précoce, aux traitements et à la réhabilitation. Bulletin du Cancer, 100, 161-165.

[6] Bey, P., Traore, F., Sylla, F., et al. (2014) Retinoblastoma: An Exemplary Tumor in Young Children That Can Be Cured in Low Income Countries. Cancer Control, 2, 111-114.

[7] Chantada, G., Doz, F., Antoneli, C.B., et al. (2006) A Proposal for an International Retinoblastoma Staging System. Pediatric Blood \& Cancer, 47, 801-805. https://doi.org/10.1002/pbc.20606

[8] Kaplan, E.L. and Meier, P. (1958) Non Parametric Estimation from Incomplete Observations. Journal of the American Statistical Association, 53, 457-481. https://doi.org/10.1080/01621459.1958.10501452

[9] Parrilla-Vallejo, M., Perea-Pérez, R., Relimpio-López, I,. et al. (.2018) Retinoblastoma: The Importance of Early Diagnosis. Archivos de la Sociedad Española de Oftalmología, 18, 30149-7.

[10] Hampejsková, L., Bascaran, C. and Zondervan, M. (2017) A Tool for Planning Retinoblastoma Services in Sub-Saharan Africa. Pediatric Blood \& Cancer, 64.

[11] Arora, R.S., Challinor, J.M., Howard, S.C., et al. (2016) Improving Care for Children with Cancer in Low- and Middle-Income Countries-A SIOP PODC Initiative. Pe- 
diatric Blood Cancer, 63, 387-391. https://doi.org/10.1002/pbc.25810

[12] Essuman, V., Ntim-Amponsah, C.T., Akafo, S., et al. (2010) Presentation of Retinoblastoma at a Paediatric Eye Clinic in Ghana. Ghana Medical Journal, 44, 10-15.

[13] Singh, U., Katoch, D., Kaur, S., et al. (2017) Retinoblastoma: A Sixteen-Year Review of the Presentation, Treatment, and Outcome from a Tertiary Care Institute in Northern India. Ocular Oncology and Pathology, 4, 23-32. https://doi.org/10.1159/000477408

[14] Sethi, S., Pushker, N., Kashyap, S., et al. (2013) Extraocular Retinoblastoma in Indian Children: Clinical, Imaging and Histopathological Features. International Journal of Ophthalmology, 6, 481-486.

[15] Sow, A.S., Ndoye Roth, P.A., Moreira, C., et al. (2014) Treatment of Retinoblastoma: Senegalese Experience. Journal Français D'Ophtalmologie, 37, 381-387. https://doi.org/10.1016/j.jfo.2013.12.009

[16] Fernandes, A.G., Pollock, B.D. and Rabito, F.A. (2018) Retinoblastoma in the United States: A 40-Year Incidence and Survival Analysis. Journal of Pediatric Ophthalmology and Strabismus, 55, 182-188. https://doi.org/10.3928/01913913-20171116-03

[17] Bellaton, E., Bertozzi, A.I., Behar, C., et al. (2003) Neoadjuvant Chemotherapy for Extensive Unilateral Retinoblastoma. British Journal of Ophthalmology, 87, 327-329. https://doi.org/10.1136/bjo.87.3.327

[18] Pant, G., Verma, N., Kumar, A., et al. (2017) Outcome of Extraocular Retinoblastoma in a Resource Limited Center from Low Middle Income Country. Pediatric Hematology and Oncology, 34, 419-424. https://doi.org/10.1080/08880018.2017.1422060

[19] Leila, S., Ibtissam, H., Hafsa, E., et al. (2016) Extra-Ocular Retinoblastoma: About 12 Cases Followed at the Mohamed VI University Hospital of Marrakech. Pan African Medical Journal, 25, 131. https://doi.org/10.11604/pamj.2016.25.131.8599

[20] Roarty, J.D., McLean, I.W. and Zimmerman, L.E. (1988) Incidence of Second Neoplasms in Patients with Bilateral Retinoblastoma. Ophthalmology, 95, 1583-1587. https://doi.org/10.1016/S0161-6420(88)32971-4

[21] Radhakrishnan, V., Kashyap, S., Pushker, N., et al. (2012) Outcome, Pathologic Findings, and Compliance in Orbital Retinoblastoma (International Retinoblastoma Staging System Stage III) Treated with Neoadjuvant Chemotherapy-A Prospective Study. Ophthalmology, 119, 1471-1477. https://doi.org/10.1016/j.ophtha.2012.01.029

[22] Bakhshi, S., Meel, R., Mohanti, B.K., et al. (2010) Treatment and Outcome of Nonmetastatic Extraocular Retinoblastoma with a Uniform Chemotherapy Protocol. Journal of Pediatric Hematology/ Oncology, 32, 42-45. https://doi.org/10.1097/MPH.0b013e3181bfcd83 